\title{
First detection and phylogenetic analysis of porcine circovirus 3 in female donkeys with reproductive disorders
}

Tongtong Wang ${ }^{1}$, Wenqiong Chai ${ }^{1}$, Yonghui Wang ${ }^{1}$, Wenqiang Liu', Zetong Huang ${ }^{1}$, Li Chen ${ }^{1}$, Ruihong Guo', Yuting Dong ${ }^{1}$, Mengyuan Liu', Qiankun Zheng ${ }^{2}$, Guiqin Liu' ${ }^{1}$, Changfa Wang ${ }^{1}$, Wen-Ping Guo ${ }^{3^{*}}$, Sidang Liu ${ }^{4^{*}}$ and Liangliang $\mathrm{Li}^{1^{*}}$

\begin{abstract}
Background: PCV3 is a pathogen associated with porcine dermatitis and nephropathy syndrome (PDNS)-like clinical signs, reproductive failure, and cardiac and multiorgan inflammation, which was newly identified in 2016 in sows in USA. Recently, PCV3 has also been identified from several non-porcine species like (cattle, dog, wild boar, deer, mice and ticks). However, PCV3 infection in donkey is not well established. Since 2019, 300 blood samples were collected from female donkey, which was characterized by abortion and sterility, in Liaocheng city of China.

Results: In the present study, an investigation of PCV3 in donkey blood samples was undertaken employing by real time PCR. Positive rates of PCV3 in donkeys reach to $21.0 \%$. In addition, one full-length PCV3 genome sequence was obtained, and it had a highest identity with porcine circovirus 3 PCV3/CN/Nanjing2017 strain and is clustered to PCV3a genotype based on ORF2 sequences.

Conclusions: This is the first report of detection of PCV3 from female donkeys presenting reproductive failure in large-scale donkey farms, China. In addition, the PCV3 strain identified in this study shared the closest relationship with those from porcine, suggesting that PCV3 may be transmitted from pigs to donkeys. Totally, PCV3 infection in donkey should be concerned although the association between it and reproductive failure are not better understood.
\end{abstract}

Keywords: Donkeys, Porcine circovirus 3, Prevalence, Phylogenetic analysis

\footnotetext{
*Correspondence: guowenping@nwsuaf.edu.cn; liusidang@126.com; lifeiyang2017@163.com

${ }^{3}$ Department of Pathogenic Biology, College of Basic Medicine, Chengde Medical University, Chengde, China

${ }^{4}$ College of Animal Science and Technology, Shandong Agricultural University, Tai'an, China

${ }^{1}$ Research Institute of Donkey High-efficiency Breeding and Ecological Feeding, College of Agronomy, Liaocheng University, Liaocheng, China Full list of author information is available at the end of the article
}

(c) The Author(s). 2021 Open Access This article is licensed under a Creative Commons Attribution 4.0 International License, which permits use, sharing, adaptation, distribution and reproduction in any medium or format, as long as you give appropriate credit to the original author(s) and the source, provide a link to the Creative Commons licence, and indicate if changes were made. The images or other third party material in this article are included in the article's Creative Commons licence, unless indicated otherwise in a credit line to the material. If material is not included in the article's Creative Commons licence and your intended use is not permitted by statutory regulation or exceeds the permitted use, you will need to obtain permission directly from the copyright holder. To view a copy of this licence, visit http://creativecommons.org/licenses/by/4.0/. The Creative Commons Public Domain Dedication waiver (http://creativecommons.org/publicdomain/zero/1.0/) applies to the data made available in this article, unless otherwise stated in a credit line to the data. 


\section{Background}

Porcine circovirus 3 (PCV3), a new member of the genus Circovirus in the family Circoviridae, is characterized by a circular, single-stranded DNA genome [1, 2]. To date, PCV3 has been found in several species, such as dogs, cattle, mice, ticks, wild boar, deer, even baboons infected by trans-species transmission by transplantation of a heart from a PCV3-positive donor pig [3-6]. In swine, PCV3 cases have been associated with porcine dermatitis and nephropathy syndrome (PDNS), multi systemic inflammation, and reproductive failure [7, 8]. Moreover, the high prevalence of PCV3 in pigs and in wild boars without specific clinical signs has been also reported [9-12]. However, the knowledge about the infection of PCV3 in donkeys is not well understood.

In the present study, 300 blood samples from female donkeys with reproductive failure from Liaocheng city, China, were tested by real time PCR for PCV3 as described previously [13]. The percentage of PCV3 infection in donkeys was $21.0 \%$. The genetic analysis of donkey-origin PCV3 shared the closest relationship with PCV3/CN/Nanjing2017strain (MK580468.1). Therefore, further research is warranted to investigate the potential of PCV3 to cause clinical disease in mares. Additionally, donkeys may serve as reservoirs for the virus, adding to the complex and poorly understood infection dynamics between pigs and other species.

\section{Results}

\section{PCV3 detection}

A total of 300 blood samples from 5 different donkey farms were tested for PCV3 using real time PCR. These results demonstrated that $21 \%$ (63/300) of the blood samples were PCV3 positive. Specifically, $24.7 \%$ $(21 / 85)$ in Chiping county, $7.5 \%(4 / 53)$ in Dong'e county, $17.0 \%(8 / 47)$ in Gaotang county, $31.7 \%$ (19/ $60)$ in development zone, $20.0 \%(11 / 55)$ in high-tech zone. The copies number of PCV3 in blood was calculated in Table S1. These results suggested the prevalence of PCV3 in donkey farms in Liaocheng city, China.

\section{Genome sequencing of donkey-origin PCV3 strain}

The fragments of PCV3 complete genome sequences were amplified as described previously [14]. After sequence assembling, the complete genome of the PCV3 from donkey named as PCV3/CN/SD-DK was 2000 nucleotides in length similar to other PCV3 strains. In detail, two ORFs, ORF1 (891 nucleotides) and ORF2 (645 nucleotides), were found, and they encoded the deduced Rep protein and capsid protein, respectively. The full-length PCV3/CN/SD-DK sequence was deposited into the GenBank database under accession numbers MW715784.

\section{Multiple sequences comparison and phylogenetic analyses}

In the current study, the complete genome sequence of PCV3/CN/SD-DK strain (indicated in additional file 1) showed $99.3 \%$ identity to PCV3/CN/Nanjing2017, and presented $97.9-99.2 \%$ identity with other PCV3 sequences. In the case of PCV3/CN/SD-DK, ORF1 shared 98.8-99.6\% nucleotide similarity with other PCV3 ORF1, and $97.0-99.0 \%$ based on the deduced amino acid sequences. However, its ORF2 gene is highly variable, shared 98.3-98.9\% nucleotide homology with other PCV3 ORF2, and 96.7-98.6\% at amino acid level. PCV3 Cap proteins from dog (CCV-A capsid protein gene KY363870), cattle (Shandong-C1 capsid protein gene $\mathrm{MH107148)}$ and mice (Nanjing-BALB-C2-MH445393) have the same discrepancy at aa residues 41 and 56 position with that of PCV3/CN/SD-DK (Fig. 1, marked in red). In addition, there are 13 positions difference between PCV3/CN/SD-DK and other variants from other species rather than donkey in Cap protein (Fig. 1, marked in green).

PCV3 can be divided into three major clades (PCV3a, PCV3b and PCV3c) based on the capsid gene sequences [15]. Considering the phylogenetic analysis of ORF2 nucleotide sequences, PCV3/CN/SDDK was genetically related to PCV3 Shandong-1 201,703 strains originated from pig, which is described as part of the PCV3a cluster (Fig. 2A). However, the phylogenetic analysis based on of $\mathrm{PCV} 3 / \mathrm{CN} /$ SD-DK complete genome (Fig. 2B) and ORF1 nucleotide sequence (Fig. 2C) were different from ORF2, and genetically related to PCV3 DE41.16 strain originated from pig, respectively. The gene sequences used in this study were listed in Table 1.

\section{Discussion}

Porcine circovirus 3 (PCV3) is a newly described member of the virus family Circoviridae, which was found to be associated with porcine dermatitis and nephropathy syndrome (PDNS), reproductive failure, and multi systemic inflammation $[1,16]$. Recent studies have suggested that PCV3 was detected in nonporcine species including domestic hosts (mice, cattle and $\operatorname{dog}$ ) and wild animals (wild boar and deer) [15, 17]. Recent years, mare abortion cause enormous economic loss in the donkey industry every year in China. Previous study suggested that EHV-1 and EAV could cause abortion of equine [18, 19], however, they are negative in present study. Interestingly, the infection of PCV3 in donkey with reproductive failure was firstly detected in our study. Therefore, we reported 


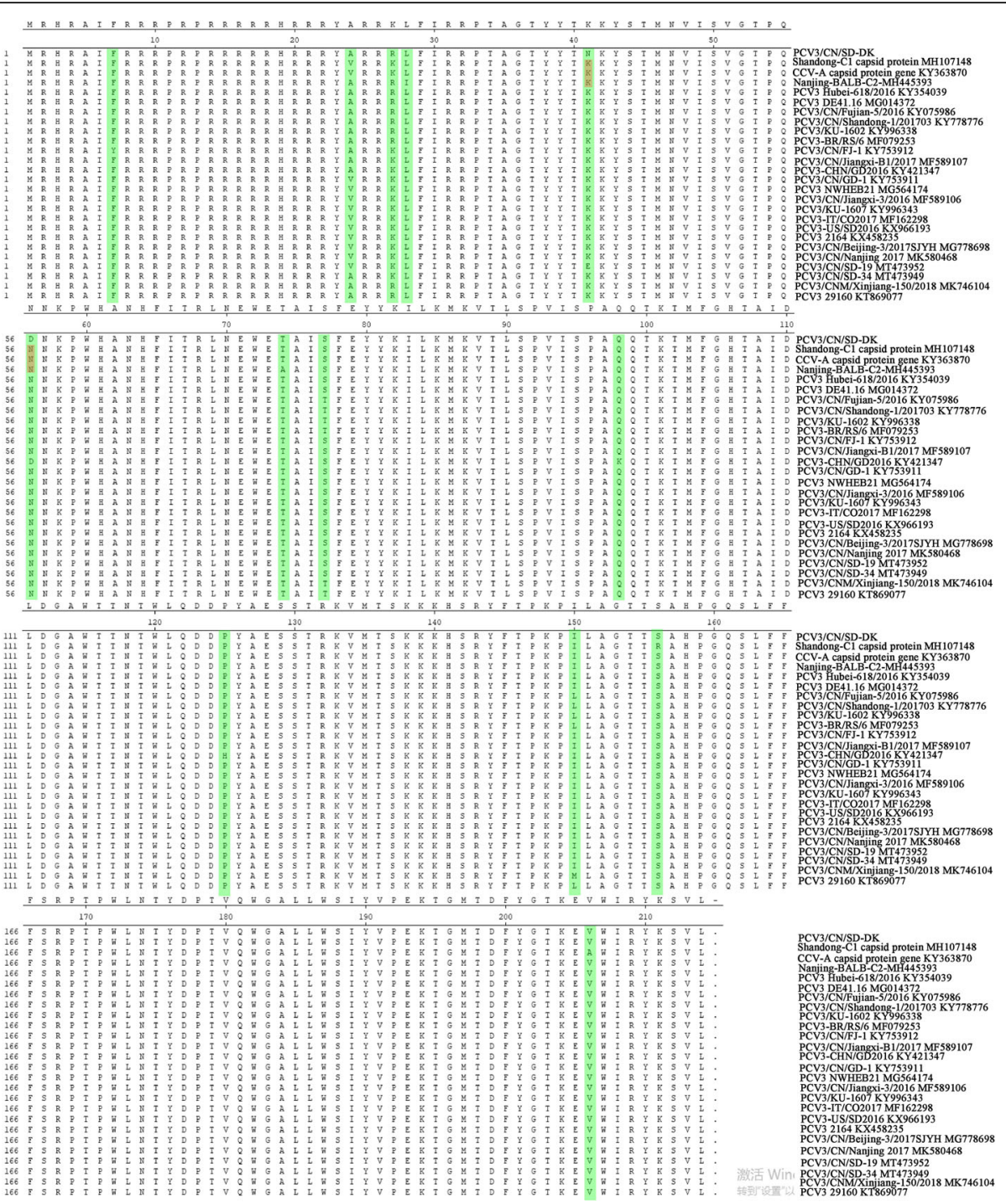

Fig. 1 Alignment of amino acid sequences of Cap between donkey with that of other species PCV3 (dog, cattle, mice and pig)

evidence of PCV3 in donkeys in China. However, the propagation and pathogenicity of PCV3 in donkeys have not been determined.

The genome of PCV3 is a 2000-nucleotide (nt) circular genome containing two major open reading frames (ORFs), ORF1 encodes a replication-associated protein (Rep), while ORF2 encodes the viral capsid (Cap) protein, that determines the antigenic characteristics of the virus $[11,20,21]$. PCV3/CN/SD-DK ORF2 gene is highly variable, shared 98.3-98.9\% nucleotide homology with other PCV3 ORF2, and 96.7-98.6\% at amino acid level. Phylogenetic tree suggested that PCV3/CN/SD-DK had a closer relationship with the PCV3 Shandong-1 201,703 strain based on ORF2 nucleotide sequences, while there are four variants of amino acids at 41, 56, 77 and 150 positions (Figure
S1). However, the comparison of PCV3 Cap from dog, bovine and mice at aa residues 41 and 56 position have same discrepancy with PCV3/CN/SD-DK Cap (Fig. 1). However, effects of these mutations of the Caps on virus infections and pathogenicity are unknown.

\section{Conclusions}

In summary, our study has provided first evidence of PCV3 frequency in donkey farm in China. The association of PCV3 with reproductive disorder in mares will be confirmed in the future. The genetic analysis and epidemiological investigation of donkey-origin PCV3 strains in this research will help enrich the data of PCV3 crossspecies transmission. 
A

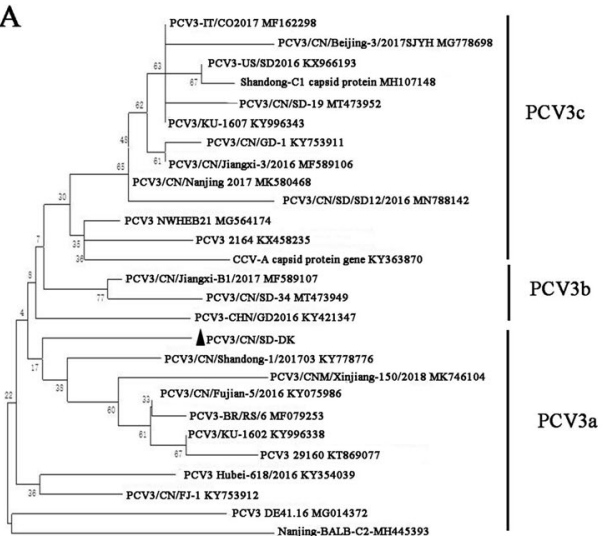

$\longmapsto$

$\mathrm{C}$

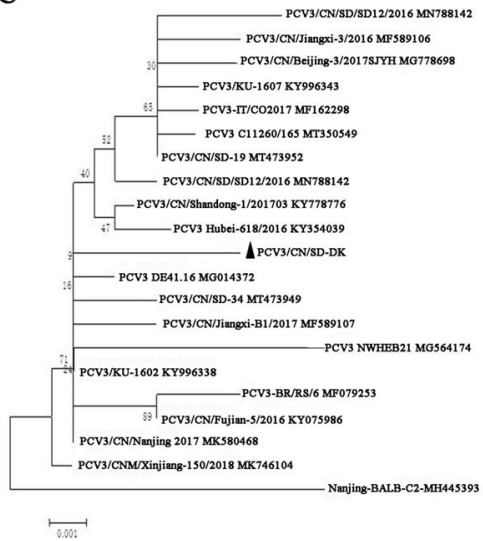

B

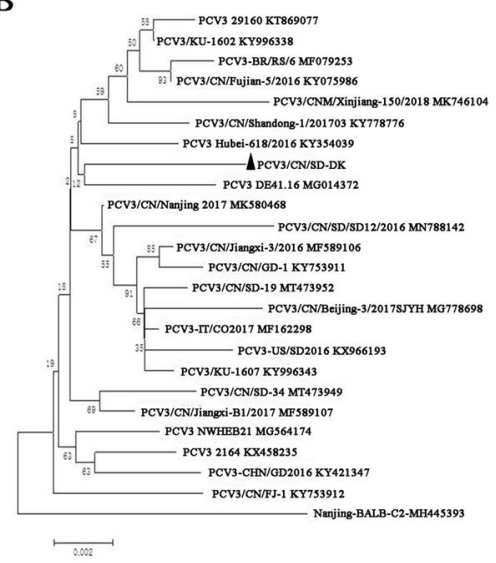

Fig. 2 Phylogenetic tree based on ORF2 (A), complete genome (B) and ORF1(C) sequence of PCV3/CN/SD-DK in this study with that of representative PCV3 (dog, bovine, mice and pig) sequences was constructed using neighbour-joining method in MEGA6.0 software. PCV3 viruses can be divided into three subgenotypes. Each reference virus is presented by the virus name and GenBank accession number. Black triangles indicate the strain detected in this study. Bootstrap values from 1000 replications are indicated for each node. The scale bar indicates nucleotide substitutions per site

\section{Methods}

\section{Sample collection}

With the permission of animal owners, we have collected 300 blood samples of 2-6 years old female donkeys with abortion and sterility (miscarring or mating more than once without pregnant) from 5 large-scale farms in Liaocheng city, China since Sep. 2019. The whole blood was collected into vacuum tubes with EDTA-K2, and stored at $-80{ }^{\circ} \mathrm{C}$ until further analysis.

\section{Viral genome extract and detection}

The viral DNA was extracted from blood samples with a Viral DNA Kit (Magen, China) according to the manufacturer's instructions. In this study, the new primers of ORF2 gene (Table 2) were designed and used to detect PCV3 as described previously with modification [13]. Each qPCR reaction $(20 \mu \mathrm{L})$ consisted of TB Green ${ }^{\circ}$ Fast qPCR Mix $(2 \times) \quad 10 \mu \mathrm{L}$ (TaKaRa, China) (the final concentration of mix was $1 \times$ ), forward and reverse primers $1 \mu \mathrm{L}$ (the final concentration of all primers was $0.2 \mu \mathrm{M}$ ) respectively, 2 $\mu \mathrm{L}$ of extracted blood DNA sample. Nuclease-free water was served as a negative control. The qPCR conditions employed the following cycling condition: $95{ }^{\circ} \mathrm{C}$ for $30 \mathrm{~s}$ and 40 cycles of $95{ }^{\circ} \mathrm{C}$ for $5 \mathrm{~s}, 60{ }^{\circ} \mathrm{C}$ for $15 \mathrm{~s}$, and $72{ }^{\circ} \mathrm{C}$ for $15 \mathrm{~s}$. The reaction efficiency and $\mathrm{R} 2$ of $\mathrm{qPCR}$ for PCV3 were determined with a dilution series of a plasmid (Cap gene cloned into pMD18-T) (Additional file 2, Fig. S2). The threshold cycle (CT) values determined from the plasmid dilution series were used to create a standard curve to determine the genomic copy number. Each assay was run in triplicates. 
Table 1 Porcine circovirus 3 (PCV3) strains used in this study

\begin{tabular}{|c|c|c|c|}
\hline Strain & Source & Country & Accession No. \\
\hline PCV3/CN/SD-DK & Donkey & China & MW715784 \\
\hline IT/CO2017 & Pig & Italy & MF162298 \\
\hline CN/Beijing-3/2017SJYH & Pig & China & MG778698 \\
\hline US/SD2016 & Pig & USA & KX966193 \\
\hline KU-1607 & Pig & SouthKorea & KY996343 \\
\hline CN/SD-19 & Pig & China & MT473952 \\
\hline CN/GD-1 & Pig & China & KY753911 \\
\hline CN/Jiangxi-3/2016 & Pig & China & MF589106 \\
\hline CN/Nanjing 2017 & Pig & China & MK580468 \\
\hline CN/SD/SD12/2016 & Pig & China & MN788142 \\
\hline NWHEB21 & Pig & China & MG564174 \\
\hline PCV3 2164 & Pig & USA & KX458235 \\
\hline CN/Jiangxi-B1 2017 & Pig & China & MF589107 \\
\hline CN/SD-34 & Pig & China & MT473949 \\
\hline CHN/GD2016 & Pig & China & KY421347 \\
\hline CN/Shandong-1/201,703 & Pig & China & KY778776 \\
\hline CNM/Xinjiang-150/2018 & Pig & China & MK746104 \\
\hline CN/Fujian-5/2016 & Pig & China & KY075986 \\
\hline $\mathrm{BR} / \mathrm{RS} / 6$ & Pig & Brazil & MF079253 \\
\hline KU-1602 & Pig & SouthKorea & KY996338 \\
\hline PCV3 29,160 & Pig & USA & KT869077 \\
\hline Hubei-618/2016 & Pig & China & KY354039 \\
\hline CN/FJ-1 & Pig & China & KY753912 \\
\hline DE41.16 & Pig & Germany & MG014372 \\
\hline CCV-A capsid gene & Canine & China & KY363870 \\
\hline Nanjing-BALB-C2 & Mice & China & MH445393 \\
\hline Shandong-C1 capsid gene & Bovine & China & MH107148 \\
\hline
\end{tabular}

\section{Viral genome sequencing}

One PCV3 genome sequence was amplified with three primer pairs of PCR (Table 2) as described previously [14]. PCR was performed using the following conditions: at $94{ }^{\circ} \mathrm{C}$ for $1 \mathrm{~min}, 35$ cycles of denaturation at
$94{ }^{\circ} \mathrm{C}$ for $30 \mathrm{~s}$, annealing at $56{ }^{\circ} \mathrm{C}$ for $30 \mathrm{~s}$, and extension at $72{ }^{\circ} \mathrm{C}$ for $1 \mathrm{~min}$, followed by a final step at $72{ }^{\circ} \mathrm{C}$ for $10 \mathrm{~min}$. PCR products of three fragments were purified with DNA Gel Extraction Kit (TIANGEN, China) and subcloned into the pCE2 vector

Table 2 The primer sequences used in this study

\begin{tabular}{|c|c|c|c|}
\hline Primers & Primer sequences $\left(5^{\prime}-3^{\prime}\right)$ & Length of product/bp & Reference \\
\hline ORF2-F & ACGTCATCTCCGTTGGAACC & 226 & \\
\hline ORF2-R & TGGAGCCAAGTGTTTGTGGT & & \\
\hline PCR1-F & ATTATGGATGCTCCTCATCGTG & 553 & (Wen, et al. [14]) \\
\hline PCR1-R & CATCTTCTCCGCAACTTCAGTC & & \\
\hline PCR2-F & GACTGAAGTTGCGGAGAAGATG & 789 & \\
\hline PCR2-R & CGGCACGAAAGAAGTTTGATT & & \\
\hline PCR3-F & CCCACATGCGAGGGCGTTTACC & 895 & \\
\hline PCR3-R & CGAGGCCGCTTCATCATCCACT & & \\
\hline
\end{tabular}


(Vazyme, China). PCV3 genome was determined and assembled using Sanger sequencing (Sangon Biotech, China).

\section{Multiple sequences comparison and phylogenetic analyses}

The complete sequences of PCV3 strains were assembled using the SeqMan v7.1.0 program (Lasergene, DNAStar, USA), and sequences homology analysis was performed using the MegAlign v7.1.0 program (Lasergene, DNAStar, USA). The information of reference sequences were downloaded from GenBank database (http://www.ncbi.nlm.nih.gov/Genbank). Phylogenetic tree was constructed using the neighbour-joining method of MEGA 6.0 software. The bootstrap consensus tree inferred from 1000 replicates is taken to represent the evolutionary history, and the neighbour-joining method was used to infer the evolutionary history $[22]$.

\section{Supplementary Information}

The online version contains supplementary material available at https:/doi. org/10.1186/s12917-021-03013-6.

\section{Additional file 1.}

Additional file 2: Figure S1. Alignment of amino acid sequences of Cap. Alignment of PCV3 isolate PCV3/CN/SD-DK and PCV3 Shandong-1 201703 strain. Figure S2. Standard curves using plasmid DNA. Ct values were plotted against the log copy number of plasmid DNA. The regression curve (y), correlation coefficient (R2) and PCR efficiency (E) were calculated.

Additional file 3: Table S1. Copies number of PCV3 in donkey blood samples.

\section{Acknowledgements}

No applicable.

\section{Authors' contributions}

T.W. and L.L. performed the research, analyzed the data, and drafted the manuscript. W.C., Y.W., W.L., Z.H., L.C., R.G., Y.D., M.L., Q.Z. contributed to the collection of samples and detection of qPCR. G.L., C.W., W.G. and S.L. revised the manuscript. L.L. conceived the study, carried out additional analyses and finalized the manuscript. All authors contributed to the revising of the manuscript. The author(s) read and approved the final manuscript.

\section{Funding}

This work was supported by the Scientific Research Fund of Liaocheng University (318051919; 318051918), Taishan Leading Industry TalentsAgricultural Science of Shandong Province (LJNY201713), and the Open Project of Shandong Collaborative Innovation Center for Donkey Industry Technology (3193308).

\section{Availability of data and materials}

All data generated or analyzed during this study are included in this published article and its additional files. The complete genomic sequence of PCV3 from donkeys generated in this study has been submitted to GenBank under accession no. MW715784.

\section{Declarations}

\section{Ethics approval and consent to participate}

All procedures was approved by the Animal Welfare \& Ethics Committee of Institute of Animal Science, Liaocheng University (protocol number LC2019-
08) and performed according to the Animal Ethics Procedures and Guidelines of the Ministry of Agriculture of China. Blood samples were collected according to the approved procedures. All owners gave informed written consent for their donkey's inclusion in the study. The study was carried out in compliance with the ARRIVE guidelines.

\section{Consent for publication}

No applicable.

\section{Competing interests}

The authors declare that they have no competing interests.

\section{Author details}

${ }^{1}$ Research Institute of Donkey High-efficiency Breeding and Ecological Feeding, College of Agronomy, Liaocheng University, Liaocheng, China. ${ }^{2}$ Delisi Group Co., LTD, Zhucheng, China. ${ }^{3}$ Department of Pathogenic Biology, College of Basic Medicine, Chengde Medical University, Chengde, China. ${ }^{4}$ College of Animal Science and Technology, Shandong Agricultural University, Tai'an, China.

Received: 4 May 2021 Accepted: 30 August 2021

Published online: 18 September 2021

References

1. Prinz C, Stillfried M, Neubert LK, Denner J. Detection of PCV3 in German wild boars. Virol J. 2019;16(1):25.

2. Chung HC, Nguyen VG, Park YH, Park BK. Genotyping of PCV3 based on reassembled viral gene sequences. Vet Med Sci. 2020;7(2):474-82.

3. Kruger $L$, Langin $M$, Reichart B, Fiebig U, Kristiansen $Y$, Prinz C, Kessler B, Egerer S, Wolf E, Abicht JM, et al. Transmission of Porcine Circovirus 3 (PCV3) by Xenotransplantation of Pig Hearts into Baboons. Viruses. 2019; 11(7):650.

4. Wang W, Sun W, Cao L, Zheng M, Zhu Y, Li W, Liu C, Zhuang X, Xing J, Lu $H$, et al. An epidemiological investigation of porcine circovirus 3 infection in cattle in Shandong province, China. BMC Vet Res. 2019;15(1):60.

5. Jiang S, Zhou N, Li Y, An J, Chang T. Detection and sequencing of porcine circovirus 3 in commercially sourced laboratory mice. Vet Med Sci. 2019;5(2): 176-81.

6. Franzo G, Grassi L, Tucciarone CM, Drigo M, Martini M, Pasotto D, Mondin A, Menandro ML. A wild circulation: high presence of porcine circovirus 3 in different mammalian wild hosts and ticks. Transbound Emerg Dis. 2019; 66(4):1548-57

7. Palinski R, Pineyro P, Shang P, Yuan F, Guo R, Fang Y, Byers E, Hause BM. A novel porcine circovirus distantly related to known circoviruses is associated with porcine dermatitis and nephropathy syndrome and reproductive failure. J Virol. 2017;91(1):e01879-16.

8. Phan TG, Giannitti F, Rossow S, Marthaler D, Knutson TP, Li L, Deng X, Resende T, Vannucci F, Delwart E. Detection of a novel circovirus PCV3 in pigs with cardiac and multi-systemic inflammation. Virol J. 2016;13(1):184.

9. Stadejek T, Wozniak A, Milek D, Biernacka K. First detection of porcine circovirus type 3 on commercial pig farms in Poland. Transbound Emerg Dis. 2017:64(5):1350-3.

10. Ye X, Berg M, Fossum C, Wallgren P, Blomstrom AL. Detection and genetic characterisation of porcine circovirus 3 from pigs in Sweden. Virus Genes. 2018;54(3):466-9.

11. Zheng S, Wu X, Zhang L, Xin C, Liu Y, Shi J, Peng Z, Xu S, Fu F, Yu J, et al The occurrence of porcine circovirus 3 without clinical infection signs in Shandong Province. Transbound Emerg Dis. 2017:64(5):1337-41.

12. Franzo G, Tucciarone CM, Drigo M, Cecchinato M, Martini M, Mondin A, Menandro ML. First report of wild boar susceptibility to Porcine circovirus type 3: high prevalence in the Colli Euganei Regional Park (Italy) in the absence of clinical signs. Transbound Emerg Dis. 2018;65(4):957-62.

13. Jiang H, Wang D, Wang J, Zhu S, She R, Ren X, Tian J, Quan R, Hou L, Li Z et al: Induction of porcine dermatitis and nephropathy syndrome in piglets by infection with porcine circovirus Type 3. J Virol. 2019;93(4).

14. Wen S, Sun W, Li Z, Zhuang X, Zhao G, Xie C, Zheng M, Jing J, Xiao P, Wang $M$, et al. The detection of porcine circovirus 3 in Guangxi, China. Transbound Emerg Dis. 2018;65(1):27-31.

15. Ouyang T, Niu G, Liu X, Zhang X, Zhang Y, Ren L. Recent progress on porcine circovirus type 3. Infect Genet Evol. 2019;73:227-33. 
16. Shen H, Liu X, Zhang P, Wang L, Liu Y, Zhang L, Liang P, Song C. Genome characterization of a porcine circovirus type 3 in South China. Transbound Emerg Dis. 2018;65(1):264-6.

17. Zhang J, Liu Z, Zou Y, Zhang N, Wang D, Tu D, Yang L, Deng Z, Yang Y, Jiang $\mathrm{P}$, et al. First molecular detection of porcine circovirus type 3 in dogs in China. Virus Genes. 2018;54(1):140-4.

18. Zhao J, Negussie H, Laval K, Poelaert KC, Nauwynck HJ. Dual infections of equine herpesvirus 1 and equine arteritis virus in equine respiratory mucosa explants. Virus Res. 2016;220:104-11.

19. Ali AA, Refat NA, Algabri NA, Sobh MS. Fetal lesions of EHV-1 in equine. An Acad Bras Cienc. 2020;92(suppl 2):e20180837.

20. Ku X, Chen F, Li P, Wang Y, Yu X, Fan S, Qian P, Wu M, He Q. Identification and genetic characterization of porcine circovirus type 3 in China. Transbound Emerg Dis. 2017;64(3):703-8.

21. Li X, Bai Y, Zhang H, Zheng D, Wang T, Wang Y, Deng J, Sun Z, Tian K. Production of a monoclonal antibody against Porcine circovirus type 3 cap protein. J Virol Methods. 2018;261:10-3.

22. Oh T, Chae C. First isolation and genetic characterization of porcine circovirus type 3 using primary porcine kidney cells. Vet Microbiol. 2020;241: 108576 .

\section{Publisher's Note}

Springer Nature remains neutral with regard to jurisdictional claims in published maps and institutional affiliations.

Ready to submit your research? Choose BMC and benefit from:

- fast, convenient online submission

- thorough peer review by experienced researchers in your field

- rapid publication on acceptance

- support for research data, including large and complex data types

- gold Open Access which fosters wider collaboration and increased citations

- maximum visibility for your research: over $100 \mathrm{M}$ website views per year

At BMC, research is always in progress.

Learn more biomedcentral.com/submissions 